\title{
Simultaneous integrated dose reduction intensity-modulated radiotherapy applied to an elective nodal area of limited-stage small-cell lung cancer
}

\author{
ZHIYAN LIU ${ }^{1}$, WEISHUAI LIU ${ }^{1,2}$, KAI JI ${ }^{1,2}$, PING WANG ${ }^{1}$ XIN WANG $^{1}$ and LUJUN ZHAO ${ }^{1}$ \\ ${ }^{1}$ Department of Radiotherapy, Key Laboratory of Cancer Prevention and Therapy and ${ }^{2}$ Department of Pain Relief, \\ Tianjin Medical University Cancer Institute and Hospital, National Clinical Research Center for Cancer, \\ Tianjin 300060, P.R. China
}

Received November 3, 2014; Accepted June 29, 2015

DOI: $10.3892 /$ etm.2015.2835

\begin{abstract}
The purpose of this study was to evaluate the clinical efficacy and toxicity of simultaneous integrated dose reduction intensity-modulated radiotherapy (SIR-IMRT) applied to an elective nodal area of patients with limited-stage small-cell lung cancer (LS-SCLC). Between January 2010 and March 2013, 52 patients with LS-SCLC that was treated with SIR-IMRT were retrospectively analyzed. A radiation dose of $54 \mathrm{~Gy}$ was administered in 30 fractions (1.8 Gy/fraction) to the planning target volume (PTV). Simultaneously, 60 Gy was administered in 30 fractions (2 Gy/fraction) to the planning gross tumor volume. Radiation-related toxicities were estimated according to the Common Terminology Criteria for Adverse Events (version 3.0). Overall survival (OS), locoregional recurrence-free survival and progression-free survival were estimated using the Kaplan-Meier method. By the last follow-up, the median follow-up time was 16.5 months, the median OS was 24.0 months, and 21 (40.4\%) patients had experienced treatment failure. Of these patients, $5(9.6 \%)$ patients developed in-field recurrence (within the $95 \%$ isodose curve of the PTV) and 1 (1.9\%) patient developed an out-of-field recurrence (not a distant metastasis). Grade 3 or higher treatment-related pneumonia was observed in 4/52 (7.6\%) patients, and grade 3 radiation-related esophagitis was experienced by $2 / 52(3.8 \%)$ patients. The results of this preliminary study suggest that SIR-IMRT is safe and effective for patients with LS-SCLC and should be further evaluated in a large prospective clinical trial.
\end{abstract}

Correspondence to: Professor Lujun Zhao, Department of Radiotherapy, Key Laboratory of Cancer Prevention and Therapy, Tianjin Medical University Cancer Institute and Hospital, National Clinical Research Center for Cancer, 22 Huan-Hu-Xi Road, Tianjin 300060, P.R. China

E-mail: tjdoctorzhao@126.com

Key words: small-cell lung cancer, radiation therapy, integrated boost intensity-modulated radiotherapy

\section{Introduction}

For limited-stage small-cell lung cancer (LS-SCLC), chemo-radiotherapy is a standard treatment and has been shown to improve patient survival $(1,2)$. However, maintenance of local control is not reliably achieved with this treatment approach, which thus contributes to the high morbidity and mortality rates observed for patients with SCLC (3). Over the past several decades, radiation dose and patterns of radiation have been varied to optimize treatment (4-7). Theoretically, the application of higher doses of radiation to a tumor should improve local control rates, and studies have confirmed that there is a positive association between tumor control and higher radiation dose (5). However, in the Radiation Therapy Oncology Group (RTOG)-0617 study of non-small cell lung cancer (NSCLC) (8), the survival time of patients receiving 74 Gy irradiation was found to be shorter than that for patients receiving 60 Gy irradiation. While the reason for this observation remains unclear, it may be due to adverse radiation-induced effects. Thus, research is ongoing to optimize radiation delivery to tumors while sparing surrounding normal structures.

Of particular interest is the application of simultaneous integrated dose reduction intensity-modulated radiotherapy (SIR-IMRT) for the treatment of malignancies $(9,10)$. SIR-IMRT simultaneously delivers a relatively higher dose of radiation to the primary disease, and a relatively lower dose to the subclinical disease or other selected regions. However, the outcome for SIR-IMRT in patients with LS-SCLC remains to be determined.

Therefore, the goal of the present study was to evaluate the feasibility of using SIR-IMRT for the treatment of LS-SCLC, and to provide evidence in support of future clinical studies.

\section{Materials and methods}

Patients. This retrospective clinical study was approved by the institutional review board of Tianjin Medical University Cancer Institute and Hospital (Tianjin, China). Between January 2010 and March 2013, patients with LS-SCLC who accepted SIR-IMRT at the hospital were included in this study. Two senior pathologists specializing in lung carcinoma reviewed all biopsy specimens, and pathologic staging was 
conducted according to the current American Joint Committee on Cancer (AJCC) criteria for NSCLC (11). All patients were evaluated for hematologic, hepatic and renal function, and also underwent chest computed tomography (CT), neck and abdomen ultrasound, brain magnetic resonance imaging (MRI) and bone scan imaging prior to receiving radiotherapy.

Therapy. The primary tumor was delineated using a lung window, while mediastinal windows were used to delineate the medial border of centrally located primary tumors, involved lymph nodes and adjacent normal organs. Gross tumor volume (GTV) was defined as any visible primary lesion present on CT simulations. All lymph nodes with a diameter $\geq 1 \mathrm{~cm}$ along their short axis were also included. The planning gross tumor volume $\left(\mathrm{PTV}_{\mathrm{G}}\right)$ was established by including a $0.5-\mathrm{cm}$ margin around the GTV. Clinical target volume (CTV) was defined as the high-risk lymph nodal regions, including adjacent regions of involved lymph nodes and the ipsilateral hilar [in accordance with the new lymph node map of the International Association for the Study of Lung Cancer (12)], including the GTV with a $0.5-\mathrm{cm}$ margin. Another $0.5-\mathrm{cm}$ margin was added to establish the planning target volume (PTV). The prescribed radiation dose, $60 \mathrm{~Gy}$ to the $\mathrm{PTV}_{\mathrm{G}}$ at $2 \mathrm{~Gy} /$ day and $54 \mathrm{~Gy}$ to the PTV at $1.8 \mathrm{~Gy} /$ day, was delivered to $\geq 95 \%$ of the $\mathrm{PTV}_{\mathrm{G}}$ or PTV, respectively. The representative dose distribution using SIR-IMRT is shown in Fig. 1. Each treatment plan consisted of five static fields with the following normal tissue constraints: i) total lung, $\mathrm{V}_{\text {lung }} 5$ (i.e., the percentage of lung volume receiving $\geq 5 \mathrm{~Gy}$ ) was $\leq 60 \%$ and $\mathrm{V}_{\text {lung }} 20$ was $\leq 35 \%$; ii) $\mathrm{V}_{\text {lung }} 40$ was $\leq 30 \%$; iii) $\mathrm{V}_{\text {esophagus }} 50$ was $\leq 50 \%$, $\mathrm{V}_{\text {esophagus }}$ maximum was $\leq 60 \mathrm{~Gy}$; and iv) $\mathrm{V}_{\text {spinal cord }}$ maximum was $\leq 45 \mathrm{~Gy}$. The definitive dose volume parameter for the organ at risk (OAR) parameter for each subject is listed in Table I. For patients who achieved a complete response (CR) following thoracic radiotherapy, prophylactic cranial irradiation (PCI) was recommended, with a dose of 25 Gy administered over 10 fractions.

Follow-up. Patient follow-up started after the radiation treatment was completed. Initially, patients were monitored 1 month and 3 months after irradiation; they were monitored every 3 months thereafter. Follow-up appointments included a chest X-ray or CT scan and a color Doppler ultrasound of the abdomen. Cranial CT/MRI and bone scans were also performed if necessary. However, regardless of follow-up stage, any symptoms that developed were immediately examined. By November 30, 2013 , the follow-up rate for this cohort was $100 \%$, and the median follow-up period was 16.5 months (range, 7-42 months).

Response assessments and toxicity. Radiation-related toxicities for lung and esophagus were assessed by two senior radiation therapists according to the Common Terminology Criteria for Adverse Events (CTCAE) version 3.0 (13). Response to radiation was first assessed 3 months after the completion of radiation based on new guidelines designed to evaluate the treatment response of solid tumors (14). These guidelines include considerations of CR, partial response (PR), stable disease (SD) and progressive disease (PD). Local recurrence was classified as in-field relapse or out-of-field relapse. The former was defined as recurrence within the $95 \%$ isodose curve of PTV. Correspondingly, $\mathrm{PTV}_{\mathrm{G}}$, GTV, CTV, and PTV recurrence were
Table I. Dose volume parameter of organ at risk (OAR; $n=52)$.

\begin{tabular}{lc}
\hline OAR & Dose volume \\
\hline MLD, cGy & $1,479.06 \pm 188.53$ \\
$\mathrm{~V}_{\text {lung }} 5, \%$ & $49.33 \pm 7.08$ \\
$\mathrm{~V}_{\text {lung }} 20, \%$ & $28.85 \pm 3.29$ \\
$\mathrm{~V}_{\text {lung }} 30, \%$ & $20.17 \pm 3.13$ \\
Esophagus $\mathrm{D}_{\text {max }}, \mathrm{cGy}$ & $6,052.50 \pm 355.46$ \\
$\mathrm{~V}_{\text {esophagus }} 50, \%$ & $42.98 \pm 14.88$ \\
Cord $_{\text {max }}, \mathrm{cGy}$ & $4,451.93 \pm 343.43$
\end{tabular}

MLD, mean lung dose; $\mathrm{V}_{\text {lung }} 5$, percentage of lung volume receiving $\geq 5 \mathrm{~Gy} ; \mathrm{V}_{\text {lung }} 20$, percentage of lung volume receiving $\geq 20 \mathrm{~Gy} ; \mathrm{V}_{\text {lung }} 30$, percentage of lung volume receiving $\geq 30 \mathrm{~Gy} ; \mathrm{D}_{\max }$, maximum dose; $\mathrm{V}_{\text {esophagus }} 50$, percentage of esophagus volume receiving $\geq 50 \mathrm{~Gy}$.

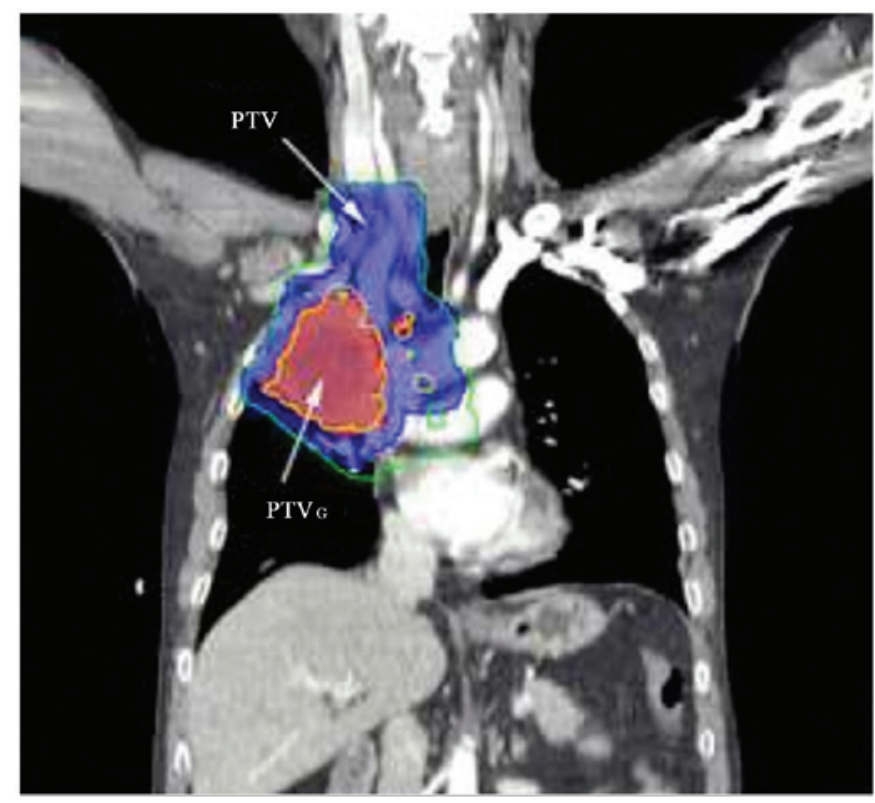

Figure 1. Representative image of simultaneous integrated dose reduction intensity-modulated radiotherapy with 60 Gy to the planning gross tumor volume $\left(\mathrm{PTV}_{\mathrm{G}}\right)$. The colored lines indicate: Red, $\mathrm{PTV}_{\mathrm{G}}$; blue, planning tumor volume (PTV); yellow, field receiving 6,000 cGy; green, field receiving 5,400 cGy.

defined as being within the $95 \%$ isodose curve of each, respectively. Regarding out-of-field recurrences, these were defined as lesions outside of the $95 \%$ isodose curve of the PTV target area that were confined to the lung, pulmonary, mediastinal and supraclavicular regions without distant metastasis (DM). Recurrences beyond these areas were considered DM events.

Statistical analysis. Statistical analyses were performed using SPSS software, version 17.0 (SPSS, Inc., Chicago, IL, USA). Using the Kaplan-Meier method, OS, locoregional recurrence-free survival (LRFS) and progression-free survival (PFS) were calculated using the pathological diagnosis date as the starting point. The endpoint for OS was the date of mortality or the date of the last follow-up; the endpoint for LRFS was the date of primary tumor detection, the date of 
Table II. Patient characteristics $(\mathrm{n}=52)$.

\begin{tabular}{|c|c|}
\hline Characteristics & No. $(\%)$ \\
\hline \multicolumn{2}{|l|}{ Age (years) } \\
\hline Median & 59 \\
\hline Range & $41-71$ \\
\hline \multicolumn{2}{|l|}{ Site } \\
\hline Left lung & $19(36.5)$ \\
\hline Right lung & $33(63.5)$ \\
\hline \multicolumn{2}{|l|}{ Type } \\
\hline Peripheral & $6(11.5)$ \\
\hline Central & $46(88.5)$ \\
\hline \multicolumn{2}{|l|}{ Gender } \\
\hline Male & $35(67.3)$ \\
\hline Female & $17(32.7)$ \\
\hline \multicolumn{2}{|l|}{ Clinical T stage } \\
\hline $\mathrm{T} 1$ & $5(9.6)$ \\
\hline $\mathrm{T} 2$ & $29(55.8)$ \\
\hline $\mathrm{T} 3$ & $13(25.0)$ \\
\hline $\mathrm{T} 4$ & $5(9.6)$ \\
\hline \multicolumn{2}{|l|}{ Clinical N stage } \\
\hline N0 & $1(1.9)$ \\
\hline N1 & $0(0.0)$ \\
\hline N2 & $28(53.9)$ \\
\hline N3 & $23(44.2)$ \\
\hline \multicolumn{2}{|l|}{ Clinical stage } \\
\hline IIa & $1(1.9)$ \\
\hline IIIa & $25(48.1)$ \\
\hline $\mathrm{IIIb}$ & $26(50.0)$ \\
\hline \multicolumn{2}{|c|}{ Induction chemotherapy } \\
\hline Yes & $51(98.1)$ \\
\hline No & $1(1.9)$ \\
\hline \multicolumn{2}{|c|}{ Adjuvant chemotherapy } \\
\hline Yes & $37(71.2)$ \\
\hline No & $15(28.8)$ \\
\hline \multicolumn{2}{|c|}{ Concurrent radiation with chemotherapy } \\
\hline Yes & $27(51.9)$ \\
\hline No & $25(48.1)$ \\
\hline \multicolumn{2}{|c|}{ Prophylactic cranial irradiation } \\
\hline Yes & $25(48.1)$ \\
\hline No & $27(51.9)$ \\
\hline
\end{tabular}

regional lymph recurrence or the last follow-up date; and the endpoint for PFS was the date that disease progression was detected or the date of the last follow-up.

\section{Results}

Patients. Fifty-two LS-SCLC patients who received SIR-IMRT were enrolled in the present study. Patient characteristics are listed in Table II. All patients completed thoracic radiotherapy. The chemotherapy regimens that were administered included

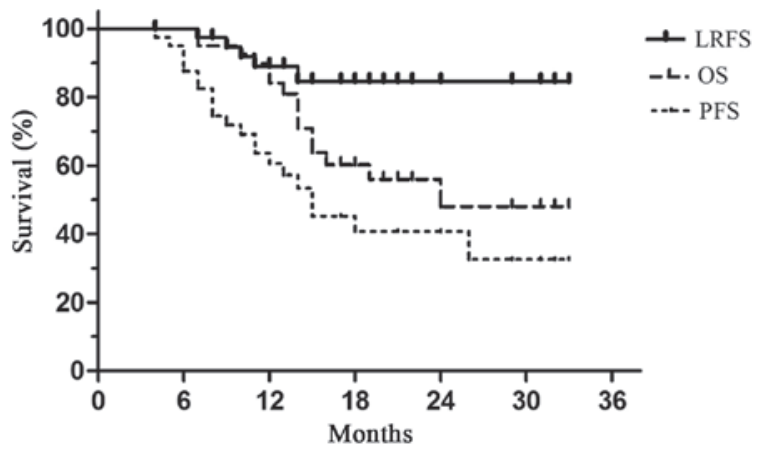

Figure 2. Overall survival (OS), locoregional recurrence-free survival (LRFS) and progression-free survival (PFS) curves for patients who received simultaneous integrated dose reduction intensity-modulated radiotherapy.

platinum-based doublets that were combined with either etoposide $(72 \%)$ or teniposide (28\%). A total of 42 patients accepted 2-4 cycles of induction chemotherapy before SIR-IMRT was performed, while 9 patients accepted radiotherapy after receiving 5-6 cycles of induction chemotherapy. In addition, 37 patients received chemotherapy after SIR-IMRT and 27 patients received concurrent chemo-radiotherapy. The 25 patients $(83.3 \%)$ who achieved a $\mathrm{CR}$ after thoracic radiotherapy underwent PCI.

Survival. Three months after completing the radiation treatment, 30/52 (57.7\%) patients and 20/52 (38.5\%) patients experienced CR and PR, respectively. The median OS for the population was 24.0 months, and the median PFS was 18.0 months. Furthermore, the 1- and 2-year OS rates were 86.2 and $54.8 \%$, the 1- and 2-year LRFS rates were 91.6 and $83.0 \%$, and the 1- and 2-year PFS rates were 68.2 and $46.4 \%$, respectively in each case (Fig. 2).

Patterns of failure. By the last follow-up, 21 (40.4\%) patients experienced treatment failure. Of these, locoregional recurrence (LRR) developed in $6(11.5 \%)$ patients, DM events at various sites were detected in $18(34.6 \%)$ patients, and $3(5.8 \%)$ patients experienced both LRR and DM. For the patients who developed LRR, $5(9.6 \%)$ had in-field recurrences [4 (7.7\%) within the GTV and 1 (1.9\%) within the CTV], and 1 (1.9\%) case involved an out-of-field recurrence. Regarding the latter case, the cervical lymph nodes were $<1 \mathrm{~cm}$ in diameter prior to treatment. A clear diagnosis was not obtained, and therefore, prophylactic neck irradiation was not administered. Detailed data regarding DM events are listed in Table III.

Treatment-related toxicity. Various grades of treatment-related toxicity were observed in this study (detailed results are provided in Table IV). Grade 3 or higher treatment-related pneumonia (TRP) was observed in 4/52 (7.6\%) patients, and grade 3 radiation-related esophagitis was experienced by $2 / 52$ (3.8\%) of patients. In particular, 2/52 (3.8\%) patients experienced grade 5 TRP. Of these two patients, one succumbed due to infectious pneumonia combined with TRP 69 days after completing radiotherapy and the other patient succumbed to TRP that was contracted 33 days after radiotherapy was completed. While the first patient accepted six cycles of induced chemotherapy prior to radiation therapy, the second 
Table III. Patterns of failure for first recurrence $(n=52)$.

\begin{tabular}{lc}
\hline Recurrence & No. $(\%)$ \\
\hline Total & $21(40.4)$ \\
Local regional recurrence & $6(11.5)$ \\
In-field & $5(9.6)$ \\
GTV & $4(7.7)$ \\
CTV & $1(1.9)$ \\
Out-of-field & $1(1.9)$ \\
Distant metastasis & $18(34.6)$ \\
Bone & $2(3.8)$ \\
Liver & $5(9.6)$ \\
Celiac lymph nodes & $4(7.7)$ \\
Brain & $9(17.3)$ \\
Adrenal gland & $2(3.8)$ \\
Heart & $1(1.9)$ \\
Pancreas & $1(1.9)$ \\
Local regional recurrence and distant metastasis & $3(5.8)$ \\
\hline
\end{tabular}

GTV, gross tumor volume; CTV, clinical target volume.

Table IV. Treatment-related toxicity $(n=52)$.

\begin{tabular}{lccccc}
\hline & \multicolumn{5}{c}{ CTCAE 3.0 grade, n (\%) } \\
\cline { 2 - 6 } Site & $0-1$ & 2 & 3 & 4 & 5 \\
\hline Lung & $36(69.3)$ & $12(23.1)$ & $2(3.8)$ & $0(0.0)$ & $2(3.8)$ \\
Esophagus & $31(59.7)$ & $19(36.5)$ & $2(3.8)$ & $0(0.0)$ & $0(0.0)$ \\
\hline
\end{tabular}

CTCAE 3.0, Common Terminology Criteria for Adverse Events, version 3.0.

patient accepted two cycles of induced chemotherapy with two cycles of synchronous chemotherapy.

\section{Discussion}

This study appears to be one of only a few clinical reports to describe the treatment outcome for LS-SCLC following SIR-IMRT. For LS-SCLC, chemo-radiation therapy is a standard treatment. In 2013, the National Comprehensive Cancer Network (NCCN) recommended that chemo-radiotherapy should include 1-2 cycles of chemotherapy followed by radiation therapy (15). The latter could include a 1.5 Gy dose twice a day for a total dose of $45 \mathrm{~Gy}$, or a 2 Gy dose once a day for a total dose of 60-70 Gy. Currently, the optimal radiation dose for SCLC remains unknown. However, certain studies suggest that an appropriate increase in total dose may improve local control and prolong OS. Correspondingly, in the RTOG 97-12 trial for SCLC (5), the total doses were 50.4, 54.0, 57.6, 61.2 and $64.8 \mathrm{~Gy}$, respectively, and the maximum tolerated dose was 61.2 Gy. Furthermore, 54/62 (87\%) patients achieved a CR (68\%) or PR (19\%), and 61.2 Gy irradiation versus 50.4 Gy irradiation was found to improve 18 - month OS rates (82\% vs. $25 \%$, respectively). In another phase II study (16), the efficacy and feasibility of accelerated radiotherapy involving a total dose of 61.2 Gy concurrent with chemotherapy for SCLC was investigated. The median survival period was 19.0 months, the 2-year OS rate was $46.4 \%$, the 2-year PFS rate was $19.7 \%$, and the median PFS period was 9.9 months. However, the results of the RTOG-0617 clinical trial showed that a higher radiation dose did not improve the survival of NSCLC patients compared to a traditional dose (8). While the reason for the latter unexpected result remains unclear, treatment-related toxicities associated with the high dose delivered to the PTV may play a role. Correspondingly, the safe application and escalation of radiation doses to a target while sparing and minimizing doses to adjacent healthy organs may be key to improving the therapeutic outcome for SCLC. At our institution, IMRT for SCLC patients includes a total dose of $60 \mathrm{~Gy}$ applied to the $\mathrm{PTV}_{\mathrm{G}}$ and 54 Gy applied to the PTV. Using this approach, the 2-year OS, LPFS, and PFS rates for the present study were 54.8, 83.0 and $46.4 \%$, respectively, and these are consistent with the RTOG 9311 study (16). It should also be noted that the present study achieved good results with a lower radiation dose, and yet the LRR for the present study did not increase compared with that observed in other studies, even though a relative lower total dose (54 Gy) was delivered to an elective nodal area. Based on these results, it appears that this dose of SIR-IMRT could benefit the LRFS and OS of LS-SCLC patients.

Some studies have found that three-dimensional conformal radiotherapy (3D-CRT) can result in a low elective nodal failure rate. This may be due to incidental radiation received by clinically uninvolved nodal regions $(17,18)$. Moreover, the amount of incidental radiation delivered to non-targeted elective nodes may differ with IMRT, and thus, may be a factor in the rate of elective nodal failure. Furthermore, it has been observed that regional recurrence continues to occur in low-dose areas (18). In the present study, elective nodal regions received radiation therapy as a preventative measure, while healthy adjacent organs were exposed to tolerable doses. Elective nodal radiation of selected high risk regions is standard for IMRT performed at our medical center. Moreover, when elective nodal irradiation was applied, elective nodal failure in the PTV occurred in only 6 patients. This suggests that relatively lower doses of radiation delivered to elective nodal regions can be sufficient to control subclinical lesions when SIR-IMRT is used. Moreover, the overall results of the present study confirm that treatment of SCLC with SIR-IMRT deserves further consideration.

The toxic side-effects reported in the present study were encouraging compared with those noted in other studies, although IMRT has been associated with fewer side-effects $(19,20)$. In the present study, 4/52 (7.7\%) cases involved TRP of grade 3 or greater, and this is consistent with previous results (21). Moreover, in a recent study of IMRT for NSCLC and SCLC, the incidence of acute esophagitis and acute TRP (grade 3 ) ranged from $18-23 \%$ and from $7-11 \%$, respectively (22). In addition, only $3.8 \%$ of patients experienced grade 3 or higher radiation-related esophagitis, and this is a lower incidence rate than that previously published (20). The use of the SIR-IMRT technique also resulted in the application of a dose gradient to the PTVG and PTV. This had the benefit of ensuring tumor dose and providing 
protection for proximal normal organs. Correspondingly, in a recent meta-analysis, symptomatic pneumonitis increased $3 \%$ when lung $\mathrm{V}_{20}$ increased by $1 \%$ (23). In addition, predictors of fatal pneumonitis were found to include a daily radiation dose $>2 \mathrm{~Gy}, \mathrm{~V}_{20}$ and the location of a tumor in the lower lobe (11).

This study had limitations. First, because the patients were not prospectively followed, selection bias and loss to follow-up may have contributed to underestimates of tumor recurrence and mortality rates. Second, four-dimensional CT examinations were not performed in this study, and this may have influenced the clinical outcomes. However, most of the primary tumors were located in the upper or middle lobes, or were central type tumors. Despite these limitations, however, the results of the present study indicate that SIR-IMRT improves patient survival and reduces toxic side-effects for patients with LS-SCLC, and also provides an intriguing justification for future studies of SCLC treatment involving SIR-IMRT.

\section{Acknowledgements}

The authors thank Medjaden Bioscience for assisting in the preparation of this manuscript. This study was supported by Nature Science Foundation of China (grant. no. 81372429) and the Project of Natural Science Fund of Tianjin (grant. no. 12JCQNJC06600)

\section{References}

1. Takada M, Fukuoka M, Kawahara M, Sugiura T, Yokoyama A, Yokota S, Nishiwaki Y, Watanabe K, Noda K, Tamura T, et al: Phase III study of concurrent versus sequential thoracic radiotherapy in combination with cisplatin and etoposide for limited-stage small-cell lung cancer: Results of the Japan Clinical Oncology Group Study 9104. J Clin Oncol 20: 3054-3060, 2002.

2. Turrisi AR III,Kim K, Blum R, Sause WT,Livingston RB,Komaki R, Wagner H, Aisner S and Johnson DH: Twice-daily compared with once-daily thoracic radiotherapy in limited small-cell lung cancer treated concurrently with cisplatin and etoposide. N Engl J Med 340 265-271, 1999.

3. Hann CL and Rudin CM: Management of small-cell lung cancer: Incremental changes but hope for the future. Oncology (Williston Park) 22: 1486-1492, 2008

4. Aridgides PD, Movsas B and Bogart JA: Thoracic radiotherapy for limited stage small cell lung carcinoma. Curr Probl Cancer 36 : 88-105, 2012.

5. Komaki R, Swann RS, Ettinger DS, Glisson BS, Sandler AB, Movsas B, Suh J and Byhardt RW: Phase I study of thoracic radiation dose escalation with concurrent chemotherapy for patients with limited small-cell lung cancer: Report of Radiation Therapy Oncology Group (RTOG) protocol 97-12. Int J Radiat Oncol Biol Phys 62: 342-350, 2005

6. Schild SE, Bonner JA, Hillman S, Kozelsky TF, Vigliotti AP, Marks RS, Graham DL, Soori GS, Kugler JW, Tenglin RC, et al: Results of a phase II study of high-dose thoracic radiation therapy with concurrent cisplatin and etoposide in limited-stage small-cell lung cancer (NCCTG 95-20-53). J Clin Oncol 25: 3124-3129, 2007.

7. Schild SE, Bonner JA, Shanahan TG, Brooks BJ, Marks RS, Geyer SM, Hillman SL, Farr GH Jr, Tazelaar HD, Krook JE, et al: Long-term results of a phase III trial comparing once-daily radiotherapy with twice-daily radiotherapy in limited-stage small-cell lung cancer. Int J Radiat Oncol Biol Phys 59: 943-951, 2004.

8. Bradley J, Masters G, Hu C, Blumenschein G, Bogart J, Schild S, Michalski JM, Kavadi V, Garces YI, Narayan S, et al: An intergroup randomized phase III comparison of standard-dose (60 Gy) vs high-dose (74 Gy) chemoradiotherapy (CRT) +/- cetuximab (cetux) for stage III non-small cell lung cancer (NSCLC): Results on cetux from RTOG 0617. Clin Adv Hematol Oncol 12: 2-4, 2014.
9. Studer G, Peponi E, Kloeck S, Dossenbach T, Huber G and Glanzmann C: Surviving hypopharynx-larynx carcinoma in the era of IMRT. Int J Radiat Oncol Biol Phys 77: 1391-1396, 2010.

10. McCammon R, Rusthoven KE, Kavanagh B, Newell S, Newman F and Raben D: Toxicity assessment of pelvic intensity-modulated radiotherapy with hypofractionated simultaneous integrated boost to prostate for intermediate- and high-risk prostate cancer. Int J Radiat Oncol Biol Phys 75: 413-420, 2009.

11. Groome PA, Bolejack V, Crowley JJ, Kennedy C, Krasnik M, Sobin LH and Goldstraw P; Cancer Research and Biostatistics; Observers to the Committee; Participating Institutions: The IASLC lung cancer staging project: Validation of the proposals for revision of the T, $\mathrm{N}$ and $\mathrm{M}$ descriptors and consequent stage groupings in the forthcoming (seventh) edition of the TNM classification of malignant tumours. J Thorac Oncol 2: 694-705, 2007.

12. Rusch VW, Asamura H, Watanabe H, Giroux DJ, Rami-Porta R and Goldstraw P: The IASLC lung cancer staging project: A proposal for a new international lymph node map in the forthcoming seventh edition of the TNM classification for lung cancer. J Thorac Oncol 4: 568-577, 2009.

13. Trotti A, Colevas AD, Setser A, Rusch V, Jaques D, Budach V, Langer C, Murphy B, Cumberlin R, Coleman CN and Rubin P: CTCAE v3.0: Development of a comprehensive grading system for the adverse effects of cancer treatment. Semin Radiat Oncol 13: 176-181, 2003.

14. Therasse P, Arbuck SG, Eisenhauer EA, Wanders J, Kaplan RS, Rubinstein L, Verweij J, Van Glabbeke M, van Oosterom AT, Christian MC and Gwyther SG: New guidelines to evaluate the response to treatment in solid tumors. European Organization for Research and Treatment of cancer, National Cancer Institute of the United States, National Cancer Institute of Canada. J Natl Cancer Inst 92: 205-216, 2000.

15. Kalemkerian GP, Akerley W, Bogner P, Borghaei H, Chow LQ, Downey RJ, Gandhi L, Ganti AK, Govindan R, Grecula JC, et al: Small cell lung cancer. J Natl Compr Canc Netw 1: 78-98, 2013.

16. Bradley J, Graham MV, Winter K, Purdy JA, Komaki R, Roa WH, Ryu JK, Bosch W and Emami B: Toxicity and outcome results of RTOG 9311: A phase I-II dose-escalation study using three-dimensional conformal radiotherapy in patients with inoperable non-small-cell lung carcinoma. Int J Radiat Oncol Biol Phys 61: 318-328, 2005.

17. Sulman EP, Komaki R, Klopp AH, Cox JD and Chang JY: Exclusion of elective nodal irradiation is associated with minimal elective nodal failure in non-small cell lung cancer. Radiat Oncol 4: 5, 2009.

18. Kimura T, Togami T, Nishiyama Y, Ohkawa M and Takashima H: Impact of incidental irradiation on clinically uninvolved nodal regions in patients with advanced non-small-cell lung cancer treated with involved-field radiation therapy: Does incidental irradiation contribute to the low incidence of elective nodal failure? Int J Radiat Oncol Biol Phys 77: 337-343, 2010.

19. Choi NC, Herndon JN II, Rosenman J, Carey RW, Chung CT, Bernard S, Leone L, Seagren S and Green M: Phase I study to determine the maximum-tolerated dose of radiation in standard daily and hyperfractionated-accelerated twice-daily radiation schedules with concurrent chemotherapy for limited-stage small-cell lung cancer. J Clin Oncol 16: 3528-3536, 1998.

20. Jiang ZQ, Yang K, Komaki R, Wei X, Tucker SL, Zhuang Y, Martel MK, Vedam S, Balter P, Zhu G, et al: Long-term clinical outcome of intensity-modulated radiotherapy for inoperable non-small cell lung cancer: The MD Anderson experience. Int J Radiat Oncol Biol Phys 83: 332-339, 2012.

21. Liu HH, Wang X,Dong L, Wu Q,LiaoZ,Stevens CW, GuerreroTM, Komaki R, Cox JD and Mohan R: Feasibility of sparing lung and other thoracic structures with intensity-modulated radiotherapy for non-small-cell lung cancer. Int J Radiat Oncol Biol Phys 58: 1268-1279, 2004.

22. Shirvani SM, Komaki R, Heymach JV, Fossella FV and Chang JY: Positron emission tomography/computed tomography-guided intensity-modulated radiotherapy for limited-stage small-cell lung cancer. Int J Radiat Oncol Biol Phys 82: e91-e97, 2012.

23. Palma DA, Senan S, Tsujino K, Barriger RB, Rengan R, Moreno M, Bradley JD, Kim TH, Ramella S, Marks LB, et al: Predicting radiation pneumonitis after chemoradiation therapy for lung cancer: An international individual patient data meta-analysis. Int J Radiat Oncol Biol Phys 85: 444-450, 2013. 